\title{
Roca Cabau, G. (2020). Pobresa i hospitals a la Lleida baixmedieval. Lleida: Pagès editors. 260 pp. ISBN: 978-84-1303-228-3
}

\section{Author:}

Frederic Aparisi Romero

Departament d'Història Medieval i Ciències Historiogràfiques de la Universitat de València. Universitat de València (València, Spain)

frederic.aparisi@uv.es

https://orcid.org/0000-0003-4520-0869

Date of reception: 29/04/21

Date of acceptance: 23/05/21

\section{Citation:}

Aparisi Romero, F. (2021). Book review: Roca Cabau, G. (2020). Pobresa i hospitals a la Lleida baixmedieval. Anales de la Universidad de Alicante. Historia Medieval, (22), 389-391. https://doi.org/10.14198/medieval.19863

\section{(C) 2021 Frederic Aparisi Romero}

Licence: This work is licensed under a Creative Commons Attribution 4.0 International License (CC BY 4.0).

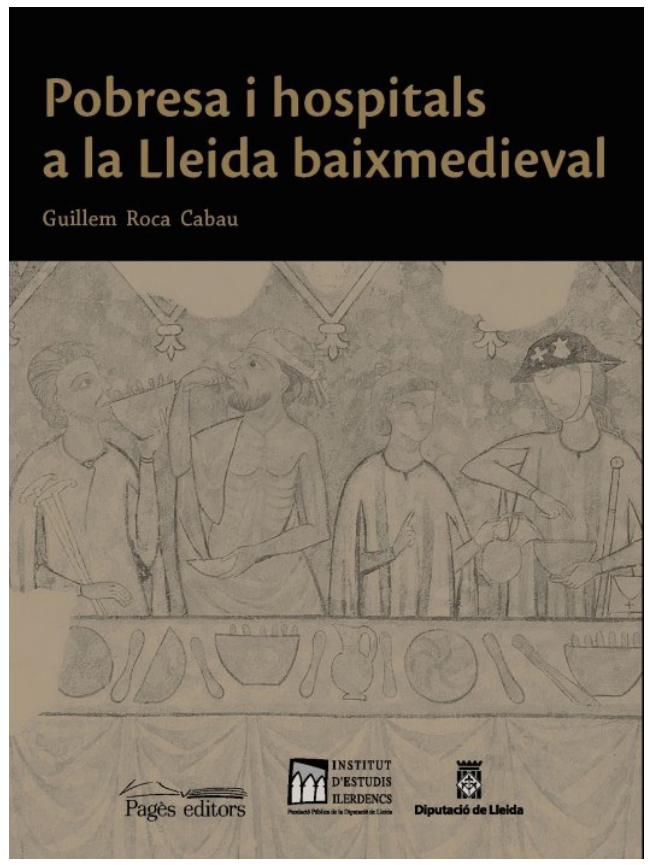

La pandèmia que vivim ha tornat al centre del debat historiogràfic les pestes $\mathrm{i}$ l'assistència mèdica en èpoques passades. I el medievalisme no ha estat indiferent a aquest corrent. A la fi i al el cap, com va dir l'insigne medievalista Marc Bloch, tota història és història contemporània. D'entre tota la producció historiogràfica que en els dos últims anys s'ha produit, i s'està produint, faríem bé de diferenciar aquella que és resultat precisament del context particular que estem vivint, d'aquella altra que forma part o és resultat de projectes de recerca a més llarg termini. Aquest és el cas de l'últim treball de Guillem Roca, Pobresa i hospitals a la Lleida baixmedieval, publicat per Pagès editors en col-laboració amb l'Institut d'Estudis Ilerdencs.

El llibre és el resultat de part de la seva tesi doctoral defensada a la Universitat de Lleida el 2017. Cal dir, però, que no es tracta d'una mera adaptació del text a les normes d'edició de l'editorial, sinó que l'autor ha portat a terme una profunda revisió dels materials i de la bibliografia per confegir un nou treball, més madur i 
assossegat. Per tot això, aquesta és una monografia destinada a durar, a consolidar-se com una referència, més enllà de modes historiogràfiques, en l'estudi de les xarxes d'hospitals i també de l'assistència a la ciutat medieval, que, al cap i a la fi, són els dos grans temes sobre els que es vertebra l'obra de Guillem Roca.

Després de la pertinent introducció, el llibre arranca amb un capítol dedicat a la definició dels conceptes de pobre i de pobresa a l'edat mitjana. En el següent capítol s'analitzen els hospitals de Lleida, des de la conquesta de la ciutat, al segle XII, fins al procés d'unificació dels nosocomis existents al segle XV. Resultat d'aquest procés seria l'Hospital general de Santa Maria, que és analitzat en detall en el tercer capítol. El quart està dedicat als usuaris dels hospitals medievals. Roca perfila els diferents trets de pobres, malalts i marginats que eren atesos en un nosocomi. Finalment, abans de desenvolupar les conclusions, es realitza una anàlisi de la xarxa hospitalària de l'entorn de Lleida i la seva evolució al llarg de la baixa edat mitjana. Per tancar, s'acompanya el treball de la transcripció d'una dotzena de documents de diversa natura que exemplifiquen els casos exposats prèviament.

Assenyalada l'estructura de l'obra, cal posar l'accent en les seves aportacions més rellevants. D'entrada, s'ha de destacar la incorporació al coneixement historiogràfic d'un nou cas particular, Lleida. No es tracta de qualsevol ciutat sinó possiblement, juntament amb Xàtiva, la principal de les ciutats la Corona d'Aragó que no era capital política de cap dels territoris que la integraven. Com digué Lorenzo Valla, tot i que Barcelona era la ciutat més puixant i bella, Lleida era la més celebre de Catalunya. Però més enllà de l'aportació d'un nou observatori, voldria destacar dos aspectes que particularitzen l'obra de Guillem Roca. En primer lloc, l'estudi dels usuaris dels hospitals medievals, i en segon l'anàlisi de la xarxa d'hospitals.

Mitjançant una aproximació a la documentació a través de la microhistòria, Roca dibuixa els diferents perfils d'aquells i aquelles que requerien dels serveis que oferien els hospitals. Sovint reduïm aquests perfils al pobre material, al pelegrí i al leprós en el cas dels hospitals especialitzats en aquesta malaltia. I és cert que tots ells són presents en aquesta anàlisi. Però Roca ens mostra un hospital més complex i, perquè no dir-ho també, més sòrdid del què el tòpic historiogràfic ens tenia acostumats. Fins al nosocomi hi arriben malfactors de tota mena, individus amb ferides encara sagnant que busquen una cura immediata i encara malalts mentals. Fins i tot, el centre esdevé l'escenari d'una violació, un fet que degué ser més habitual del què les fonts il-lustren. Aquesta perspectiva que situa en el punt de mira el malalt més que no l'assistència o la malaltia en si mateix resulta força interessant i obri una línia d'anàlisi poc transitada en l'estudi de la salut a l'edat mitjana.

La segona de les aportacions d'aquest llibre és dibuixar, amb el detall que permet la documentació, la xarxa hospitalària de l'entorn de Lleida en època medieval. Paga la pena insistir en el fet que l'estudi de les xarxes hospitalàries va més enllà de la simple enumeració de nosocomis, per bé que l'inventariat és el primer pas necessari 
i indefugible. Però com Roca ens demostra, les xarxes hospitalàries canvien amb el temps i són reflex de les situacions de cada moment. Per això no hi ha una xarxa hospitalària medieval sinó més aviat xarxes, en plural, perquè cada segle, cada context històric, va tenir la seua pròpia xarxa d'hospitals. De retruc, Roca ens il.lustra sobre la xarxa de camins que conduien fins a la ciutat de Lleida o que partien d'ella.

Tot plegat, estem al davant d'una obra madura, tot i la joventut del seu autor, ben pensada i assossegada, que s'insereix de ple en dels debats que estan de rabiosa actualitat en el medievalisme i en el conjunt de la historiografia. 